\title{
Directing Technology to Encourage Creativity amongst Digital Arts Practitioners
}

\author{
Vesna Maljkovic \\ Simon Fraser University, Canada
}

\begin{abstract}
With the increase of local companies in digital media arts industries [1] and the number of job opportunities within those industries [2], the number of local media arts educational programs is on the rise as well [3]. Students who attend these programs are often expected to master artistic skills within one or two years without any previous experience or knowledge and in this process, they depend heavily on digital technology. A key area of concern focuses on novice digital artists' dependence on technology and the tendency for this dependence to detract from their ability to express artistically, think critically and analytically, and transfer their acquired skills into life/work settings. Maybe one way to address these concerns would be to review the teaching/learning processes, potentially postpone the focus on technology and instead offer an education where learners have the opportunity to develop toward their desired goals while building on their strengths and previously acquired knowledge. The purpose of this paper is to explore how digital media arts students can be supported in their artistic journeys in ways that meet their needs and graduation expectations.
\end{abstract}

\section{Introduction}

Since the late 1990's, Vancouver continues to sustain its position as a leading North American centre in digital arts industries [1] and the number of job opportunities within those industries is on the rise [2]. According to a Tech Vibes [3] article, "Vancouver alone has more than 800 companies in digital film, animation and visual effects, video games, mobile content and applications, and elearning. These companies are generating $\$ 3$ billion in revenue annually." Further to that, Creative BC [4] reports that "BC's Interactive + Digital media sector is one of the most dynamic engines in the $\mathrm{BC}$ economy and is a key driver of skilled jobs that will define the future of the province." Digital entertainment and interactive media are generally divided into three areas: Visual Effects \& Animation, Video Games \& Interactive Media, and Film \& Television Production. Reporting on one of the areas, Video Games \& Interactive Media, Entertainment Software Association of Canada (ESAC) [5] reveals the vital data:
The Canadian industry saw a 38 percent increase in the number of active studios in the two-year span between 2012 and 2014 (from 328 to 472 active studios). Employment gains were similarly impressive, with 20,400 full-time equivalents (FTEs) employed in 2014, up 24 percent from 16,500 in 2012 (p. 6).

However, despite the predicted glorious future of the industry, there are noted serious challenges, namely talent acquisition. The same report by the ESAC [5] points out that "companies struggle to find and attract highly skilled workers to lead domestic teams and keep up with demands of the global market" (p. 4). As a result of the rapid growth of this sector and recognizing this demand, both public and private educational institutions have invested in developing related educational programs. For example, the BC Council for International Education team visited one of the local digital arts institutes specializing in fields such as animation, visual effects, and game art and design. After the tour, they reported [6] that from game design to $3 \mathrm{D}$ animation and visual effects, Vancouver's digital arts schools are on the world map. Students graduate with skills that are in high demand and companies open doors here just to tap into the local talent. Some local digital arts schools, predominantly from the private sector, offer one or two-year certificate and diploma programs where students are expected to master required skills often within the duration of these programs without any previous experience or knowledge. And, often during this process, they rely heavily on digital technology. My role as an Academic Director for the digital arts department at the local post-secondary institution allows me to note an increased number of enrolled students in digital arts programs. However, despite the excellence in teaching and award-winning curricula, I have also noted that digital arts students often face numerous issues when it comes to educational experiences and graduating outcomes.

A key area of concern focuses on novice digital artists' dependence on technology and the tendency for this dependence to detract from their ability to express artistically, think critically and analytically, and transfer their acquired skills into life/work settings. Maybe one way to address these concerns would be to review the teaching/learning processes and potentially postpone the focus on technology and 
instead offer an education where learners have the opportunity to develop toward their desired goals while building on their strengths and previously acquired knowledge. Nevertheless, whether that concept proves as achievable in the mentioned settings, the purpose of this paper is to explore how digital arts students can be supported by educators in their educational journeys to meet the needs and expectations of all stakeholders involved (i.e. learners, parents/guardians, community, and the related industries).

In order to explore the importance of the development of artistic skills with the use of technology I consider three increasingly deeper layers in relation to the topic. The starting layer of the topic focuses on the educational computing, and its role in the digital arts education classes. The next layer explores the aesthetic experience of art and artistic processes within those classes. In the third and the final layer I draw upon several concepts from critical pedagogy and on my experience as an arts educator within digital arts education. I raise questions regarding the incorporation of technology into artistic expression and experience, with the aim of revealing how digital arts students can be supported in their artistic journeys in ways that both meet their needs and graduation expectations.

This paper concludes by addressing the implications of the digital arts classroom practices we constructed in response to rapid growth of the media arts industries. Specifically, it cautions on the warning signs of increased practices of training versus education, and the fundamental issues existing in the current educational landscape by asking the question: are we ceasing to educate our graduates, and instead are we only training them for jobs? In that last section, I reveal my deep concerns about the knowledge economy and commercialization of higher education. I conclude the essay by providing the rough sketch of the conceivable but not yet actualized educational landscape.

\section{Digital technology in teaching and practicing art}

Although adoption of digital technology in teaching and practicing arts is often recognized as a positive transition [7], in some cases research shows it as unnecessary and too early in the artistic process [8]. However, since we live in the $21^{\text {st }}$ century and we are constantly surrounded by digital technology, this union of traditional art and digital technology is inevitable, and in most cases already present. And while the once passionate discussion regarding the value of this union is slowly settling down, and progressively more arts educators are utilizing digital technology in their classrooms, the main inquiry shifts from the question of whether to adopt new digital tools, to how much we rely on them. The direction of an arts education discourse is shifting from the breadth of education, namely the incorporation of information and computer technology (ICT) to the K-12 and post-secondary arts education curriculums, to the depth of education, specifically the art creation process, regardless of the medium used. Since there is still a significant resistance from the art educators to remain within the traditional art realm when it comes to artistic expression, the following question has formed: is it necessary for digital artists to map their artistic processes first (understanding why and what they wish to create) and then choose suitable media, traditional or digital (proposing how they are going to create it) in order to achieve desired outcomes (produce art pieces)? In an attempt to answer this question, the starting point is to look at literature related to this topic from a few different points of view.

\section{Review of Literature}

\subsection{Early adoption of digital technology in traditional art classes}

Despite the fact that today's learners are digital natives, and they are accustomed to learning through digital technology, there is still significant resistance from art teachers to the idea of creating art on and with computers [7, 8]. For example, in 2014 Örtegren [9], published the study of a group of one secondary school's teachers and students where he reported their mixed attitudes toward the digital technology in arts education classes and processes. Given the number of voices for and against these processes, this study is a great illustration of the current arts education discourse. According to Örtegren [9] "Media ecology studies and takes an interest in how different forms of communication media affect human beings' perceptions, understandings, feelings and values" (p. 195). The aim of his study is to explore how different aspects of the implementation of digital media to art courses in secondary schools might be related to the subject of paradigm shifts. The author implemented the concept of "the sacred and the profane" where the sacred are all the aspects that are significant to the subject of art, and the profane refers to aspects that change and challenges the sacred.

Örtegren [9] reports "how digital media find an expression in the Art subject has depended on the teachers' and pupils' respective use in connection with Art teaching" (p. 198). Several of the research participants' voices show that artistic experience is their focus (the sacred) and they report a gap between fine art and technology (the profane). For example, one of the teachers shares his opinion: "...I have tested this Sketchpad, is that you lose the sensual aspect. The feeling of having a piece of paper with a structure and can feel frictions" ( $p$. 200). And one of the pupils shares her experience: "Because when you draw on the computer you don't sketch in the same way, then you don't get the same 
idea" (p. 202). Further, Örtegren reports that teachers feel pupils have fewer opportunities for selfreflection during the production process, and that the 'sacred' for many teachers is the pupils' personal art development.

The report, which uses both teachers' and pupils' voices states the 'sacred' is the pupils' personal development and artistic experience, and the 'profane' is the process of forced digital media adoption. However, we have to keep in mind that "[a]ll teachers tend to teach as they have been taught, and clearly few, if any, have been taught to use new technologies as either art media or teaching tools" [8]. For that reason, there are still some teachers that report worries: "The teacher pointed out a problem with leisure work with art, namely the quality. Drawing and painting have decreased and photography and film have increased as leisure activities" (p. 209), which could be recognized as 'profane' or forced digital media adoption [9].

Nevertheless, Örtegren [9] still argues: "The addition will successfully increase as the teacher didactically tries out new digital tasks and projects and brings them into the year planning" (p. 201) and presents this addition as an ultimate goal. He reports that digital media is used mainly in the process of research, inspiration, and as a model for further processing (e.g. wider distribution of finished products). Until those conditions are changed, "we can assume that media ecology will arise that might come to be required to ensure a higher degree of fusion between analogue and digital image production" [9] (p. 212). Having said that it is important to ensure the higher degree of fusion that Örtegren is proposing does not only entail replacing older with newer media, such as traditional photography dark room process with a newer digital photography editing process, but rather recreating the creative journey that will offer the essential artistic experience.

Although Örtegren's research questions were focused on the use of the digital media in the subject of Art, unanticipated results show us that artistic aspect of the practice is very important and should be taken into consideration. For example, one of the participants (teacher) illustrates her requirements for documentation of the creative process [9]: "It is not enough that the product is well made. What have you done yourself, and how did you think?” (p. 207). It is not the accomplished end product that is important to some of these teachers, but rather the experience and critical thinking that is happening along the way. As mentioned before in reference to the media ecology, it is evident that different forms of communication or media are chosen so that they may be more suitable for these artists, and more importantly their art projects. Since we are all surrounded by different types of art than even ten years ago we can expect these young artists to take inspiration from what they are exposed to. Oversized billboards floating in the sky that are depicting beautiful digital photographs of pristine beaches, sleek curved new cars, shiny new apartments for sale is just the beginning. The rest of the exposure comes in as a form of music videos, Instagram postings, YouTube shorts delivered to their mobile devices or laptops. Very rarely does today's average teenager have the opportunity to observe and analyze an oil painting long enough to become inspired to create something similar by the means to reflect their thoughts and emotions. Instead, they will unpack the latest video game they played and utilize the latest technology available, intending to create something of their own, just as many artists did before them. As John Dewey [10] explains: "For the doctrine did not signify that art was a literal copying of objects, but that it reflected the emotions and ideas that are associated with the chief institutions of social life" (p. 7). In addition, digital artists similar to traditional artists might not know if their digital photographs or films are art until art experts discover it and label it as such. Dewey [10] observes:

Domestic utensils, furnishings of tent and house, rugs, mats, jars, pots, bowls, spears, were wrought with such delighted care that today we hunt them out and give them place of honor in our art museums. Yet in their own time and place, such things were enhancements of the processes of everyday life ( $p$. $6)$.

The notion that something very common cannot be art is dismissing the possibility of digital media because of its accessibility. Nevertheless, "the paradigm of the subject of Art may be shifted in a more communicative way" [9] as it is becoming more evident in some communities as well as arts communities. For example, we witness openings of new media/digital art galleries as well as traditional art galleries incorporating an increased number of digital art exhibitions. Another one of the recent examples of such paradigm shift is the project cofounded by Dr. Ian Cook, Associate Professor at the University of Exeter and Paula Crutchlow, independent artist and performance maker called Museum of Contemporary Commodities (MoCC). Cook and Crutchlow, along with their team, collect, interpret, and group commodities as our future heritage. According to them $\mathrm{MoCC}$ is "neither a building nor a permanent collection of stuff - it's an invitation" [11].

Though not directly addressing the aspect of artistic process, through technological progression we can expect to recognize increase of merge between analogue and digital image production. Also, it is important to note and support a recurrent choosing to allow perception of digitally produced creations as art. Again, Dewey [10] reminds us that:

It is not so easy in the case of the perceiver and appreciator to understand the intimate union of doing and undergoing as it is in the case of the marker. We are given to supposing that the former merely takes in what is there in finished form, instead of realizing that this taking in involves activities that are 
comparable to those of the creator. But receptivity is not passivity. It too is a process consisting of a series of responsive acts that accumulate toward objective fulfillment (p. 54)

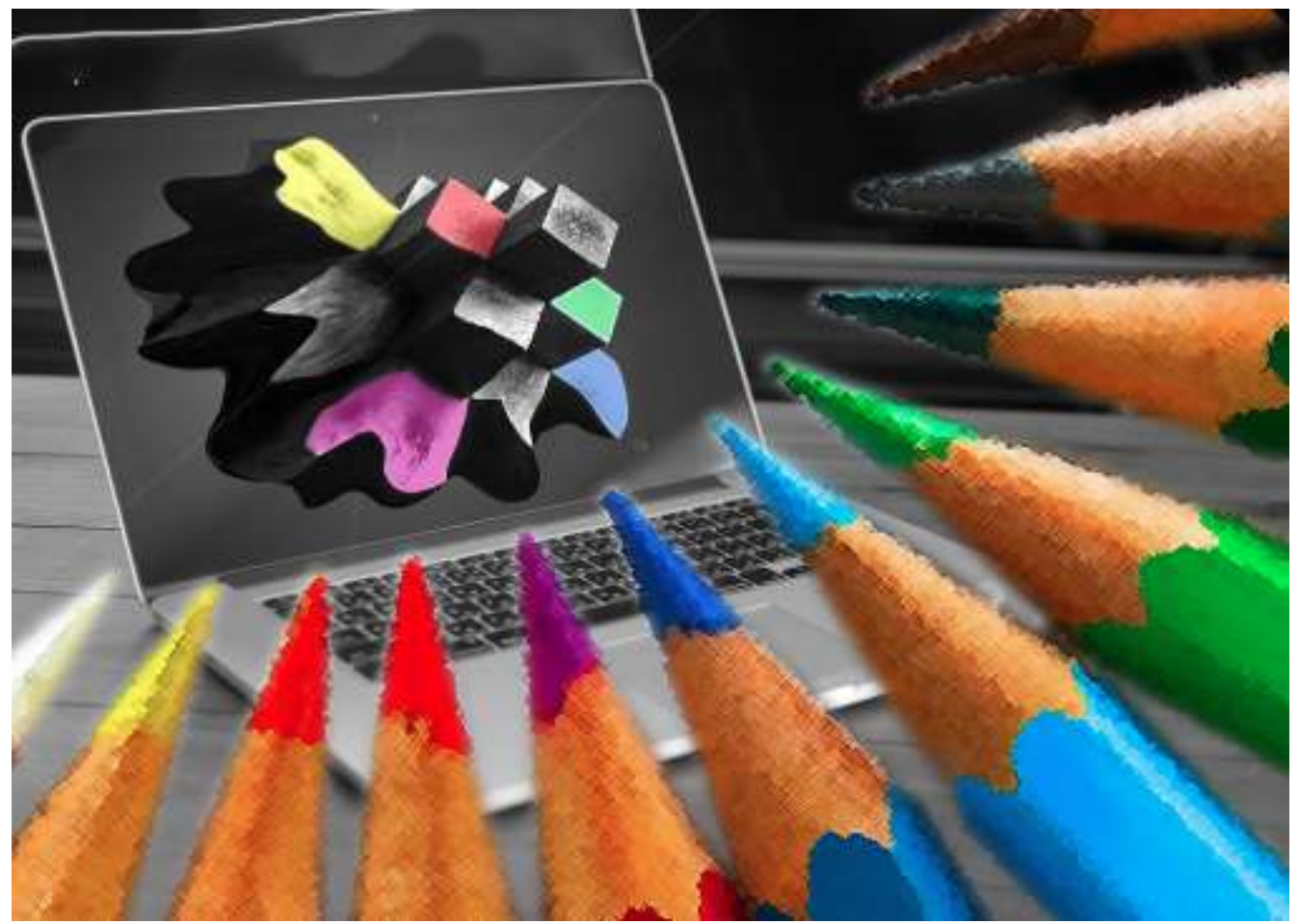

Figure 1. Artigital One, Digital collage, image published with permission

As the new viewpoints are emerging we are discovering the new opportunities on this journey toward the high degree fusion between arts processes and computers (Figure 1).

\subsection{Digital technology as focus}

Even though many artists identify somewhere in between the two extremes, on the other side of the traditional art - technology spectrum there is a group of "art techies" who are considering technology as positive addition to their artistic processes and are enthusiastically developing the means to utilize technology more and more. However, the real question is not whether we are willing to (mindlessly) use technology but it is how to adopt it and benefit from this new relationship. Since many artists are describing computers as tools used in their artistic processes, Sherry Turkle [12] is asking: "If the computer is a tool, is it more like a hammer or more like a harpsichord?" (p. 8). She continues to explore the notion of a computer's second nature that we can delve into further. Turkle [12] recommends: "Recognizing the computer's second nature as an expressive medium is important for those educators who work with educational software as well as for those who [use] programming as a stepping-stone to other learning" (p. 8). An interesting example comes from my own surrounding: My anecdotal conversation with one of the tech enthusiasts and a traditional clay artist who uses sculpting computer software in his art process explaining his perception of computer's second nature notion: "When working with sculpting software results could be very unpredictable, sometimes positive, sometimes negative. It is like when you take your glazed pieces out of the kiln - you never truly know how will that combination of glazes turn out." The main difference might not come from the final results but from the process: working on a computer appears to be inexpensive in the long run compared to the glazes. He continues:

When one makes a mistake on a computer they can simply undo an error adding comparatively little time cost to the project, and when one makes a mistake with firing glazes that could add significantly more time and monetary cost which helps understand the significance of thorough planning process. Lessons learned from traditional process might be more profound, however learning experience in the digital setting appears to be safer with less risks involved.

Black \& Browning [8] warn us:

...art teachers typically use established computer technologies as teaching or presentation tools rather than facilitating student's creative production and thinking, collaborative learning, problem-solving and higher order learning... [Yet art] teachers have the capacity for creative thinking, problem solving, and risk taking... (p. 20).

If in the description of benefits for utilizing computer software in the art creation process, we use 
terminology as safe, less expensive, less risk involved, that there is a worry that this fusion is short sighted and superficial. Instead, there is an evident need for art educators to understand the true meaning of high fusion of arts and technology. Black and Browning [8] argue that:

An important approach to teaching digital arts is recognizing that students need not comprehend all that there is to know about the software. Rather, students can learn the software through the act of creating. Technology, however, should not be the most important part of the learning process; rather, the artmaking process is key. To this end, students can be encouraged to manipulate and play with digital objects and ideas (p. 21).

Turkle [12] explains two main approaches to the work with computers: planning and bricolage (tinkering). She argues that when planning approach is incorporated, mistakes might be experienced as missteps. However, for bricolage (tinkering) approach mistakes are stepping-stones in a process due to the fact that linear advancement is not important. Turkle [12] points out "this style of work is highly interactive, more like a conversation with the computer than a monologue" (p. 8). She continues explaining that this dichotomy between planning and bricolage is only one aspect of how computer users differ in their styles and approaches and it could be a good starting point for recognizing vast diversity of learning styles. However, my own observation of different classrooms shows using bricolage requires confidence and that not all students are on the level. In addition, not every school or teacher are receptive to the tinkering students - overcrowded classrooms, lack of resources and technical support will leave very little one-on-one time for teachers to spend with their students which would be necessary component for the bricolage approach. Turkle [12] suggests a similar notion: "Provided with software that makes it hard for them to maintain a flexible style, some students 'hack' the system trying to make it more suitable to their intellectual styles. Others simply give up" (p. 8). This option of giving up could have been possible for students one or two decades ago when technology was not such an important part of everyday life, however presently studios and even some postsecondary schools may expect students to have a solid basis in using art creation software as an entry requirement. Because giving up is not an option anymore, students and educators need to support learning in every environment. Turkle is aware that educational computing is often not part of the supportive learning environments' practices. She spends much of her article arguing for the notion of epistemological pluralism and lack thereof in educational computing. Thus the essence of her criticism reads [12]:

Many children like Anne follow in the path of a Lisa; that is, they begin to "fake it" in order to get by. Or, like Rachel, they begin to work in "cookbook" style. Such "escapes to conformity" muffle the expression of "different voices" in computing. But these voices are there. They re-emerge when people are given flexible tools and a permissive environment in which to use them (p. 8).

With such expectations of high degree fusion between arts processes and computers there is a need of thorough understanding of attainable technology support hence Turkle's [12] metaphor: "If the computer is a tool, is it more like a hammer or more like a harpsichord?" (p. 8). Students are expected to perform a balancing act on the tightrope between traditional arts and digital arts technology to be able to achieve desirable outcomes. If they lean toward one side the computer may change from a harpsichord to a self-playing piano which might be valuable in some automated practices but not in the process of arts. Black \& Browning [8] offer a solution:

Teachers do not have to know everything about the software; they need only be willing to take a creative approach to technology and learn from their students. If the perspective of the visual arts teacher is "pro-tech" (meaning that they put the technology first), then students may complete mechanical assignments that do not creatively express the self. Most importantly, the creative individual should drive technology, and as students creatively explore art assignments they may learn not only the software, but also express themselves creatively (p. 21). Conclusively, as tempting as it is to incorporate digital technology into the arts processes, artists would need to demonstrate a thorough understanding of the artistic map first to be able to adapt technology and utilize it to its capacity. Only when we direct technology to serve our needs we can expect to acquire desired outcomes.

\subsection{Use of digital technology in arts practices}

Going beyond classrooms and looking into the art communities there are many contrasting opinions when it comes to the use of technology in arts practices. While we observe the increase in digital photography in arts communities such as art galleries and public art spaces, other forms of new media art are still not being fully integrated. As noted earlier and from my own experience on the arts-technology spectrum on one side there are traditional artists. There is an evident resistance from many traditional arts educators and practitioners to utilize technology in their arts processes even as limited as data management and dissemination practices. In 2015 Coles and Pasquier [13] published their three-year research study that was initiated with three filed work locations: Big Island of Hawai'i, USA, Vancouver, Canada, and Amazon River region, Colombia. In their research Coles and Pasquier [13] aim to question the possibility for an individual to, by the means of digital technology, experience an awareness of connection with nature within natural 
settings. For this multifaceted investigation, they chose interpretive arts-based research and phenomenological observation methods. Besides art and technology, the third aspect of their enquiry involved nature. Diversity of the participants, uniqueness of the research and admirable example of appropriately directed technology marks this study as a valuable representation of the arts communities' discourse.

Coles and Pasquier [13] illustrate their position: "Cave paintings bear witness that, early in the human cultural development, art and the means to create it (technology) became a method of expression and translation of human interconnectedness with nature as the non-human-made world" (p. 3). Coles and Pasquier [13] state with their proposal that "the human-technology-nature relationship may be a conduit or provide a sensorial pathway to establishing a reconnection to natural realm through the use of digital technologies in situ" (p. 4). Authors used artistic expression as a means to demonstrate this process. Focus is then placed on the particular style of electronic arts often positioned in natural settings. Such artists can "use a natural setting as a partner in both the creation and display of artwork that is inclusive of technology" [13] (p. 7). This emerging genre is recognized as digital eco-art. Since art in general and particularly digital eco-art is a non-invasive method of interacting with nature it is not surprising that this study reported positive results.

Findings show that digital technologies are not always perceived as unnatural. According to the authors this opens up transformative possibilities in other realms of our society such as politics, health, education and more. Furthermore, the authors then continue with a report on the research process that included pre-interviews and post-interviews conducted with twenty-four spectators and six artists. Out of twenty-four pre-interviews four shared their skeptical thoughts when it came to technology and nature. The authors report one of the spectators describing a computer as a tool, others used the terms object or dead and one of them expressed anger toward digital technology and complained about the dehumanizing effects such technology has on society.

In the post-interview [13], all four previously skeptical participants changed their perceptions of nature and technology and reported that their experiences "felt nice, symbiotic, peaceful, or pleasant" (p. 11). Further the authors report [13] that in the pre-interviews three out of six artists demonstrated skepticism toward the technologynature relationship and the post interviews illustrated change: "they sensed interconnectedness and they were surprised by it" (p. 12). 'Human-technologynature Triad Relationship' is a noticeably important research project that will assist with potential transformation of the common notion of humannature alienation as a result of technology.

As technology continues to develop and humans continue to strive toward it, value of this research study might be on the rise as Louv [13] remind us:

The future will belong to the nature-smart - those individuals, families, businesses and political leaders who develop a deeper understanding of the transformative power of the natural world and who balance the virtual with the real. The more high-tech we become, the more nature we need (p. 4).

Another commendable example of the high fusion of art-technology-nature is a student production at the LaSalle College Vancouver, under the lead of Ran Sieradzki, working with local indigenous artists to bring awareness to the environmental crisis we are facing nowadays. Students produced an animation short where heroes who are portrayed as animal-humans are fighting the dark spirits that are threatening to invade and destroy their forest. For the creation of this art piece these students utilized many modes of art making in their production pipeline. These modes include oral storytelling, hand-drawn concept design, storyboarding, both traditional and digital character and sets design and modeling, digital illustration, high-end computer rendering and more (Figure 1, Figure 2).

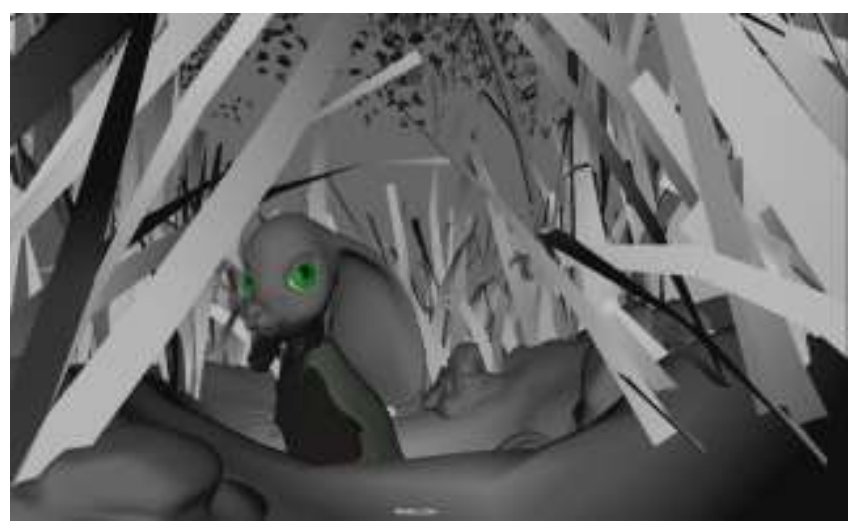

Figure 2. Mouse-woman spots a danger, Work in progress computer render, image published with permission 


\section{Exploring the Artistic Process}

As previously mentioned, a key area of concern focuses on novice digital artists' dependence on technology and the tendency for this dependence to detract from their ability to express artistically. To better understand all implications of this occurrence I will draw on Wollheim's [14] notion of an 'appropriate experience' of a spectator. According to Wollheim [14] there should be a visual experience of a picture, in terms of which its representational properties are to be explained. He continues to argue that very often 'appropriate experience' will fail based on the two sets of circumstances: one, when the intentions of the artist are too confused or too abstract; and two, when artwork is too inept or too insensitive. Both cases result in two possible outcomes: "One is that the artist's intentions have not been fulfilled, either because the intentions were unfulfillable or because the work failed to fulfill them. The other is that the work lacks meaning, or is not to be understood" (p. 132). As has been mentioned, my observation is that digital media arts, produced at schools, often fails to satisfy conditions for the 'appropriate experience' of adequately sensitive and adequately informed spectators. The reason for that might be in the artistic process, that appears to be too superficial or too incomplete. This lack of the process has serious implications not only on the spectators' experience but on the artists' outcomes as well and particularly their mental state. Benson [15] elaborates this idea by arguing that pictorial meaning is triadic: "It is located in the mental state of artists, the way in which this causes them to paint, and the experience that an informed and sensitive spectator can be expected to have on looking at their pictures" (p. 193). Benson [15] goes on to explain that "the spectator's being at any point is contingent on where in the flow of the experience he or she is, on where, that is, he or she is positioned in the unfolding work that is art as experience" ( $p$. positioning we need to focus on the artistic process and creation of art as experience.

To be able to produce art - traditional or digital one needs to understand the art process. What constitutes art and more so how do we know that we are experiencing art? Benson [15] starts the exploration by illustrating the aesthetic experience: "If the pain of deliberately inflicted torture

epitomizes negative absorption, then the expansion of self that occurs in aesthetic experiences of art typifies its antithesis, positive absorption" ( $p$. 176). It is the idea of 'expansion of self' that unfortunately is not very much represented in digital arts schools and yet it is imperative for the educational processes. Benson [15] continues explaining that during the experience of art one develops the feeling of what they want to be, even temporarily. To expand this notion, he uses the metaphor of being moved while experiencing art such as listening to music, painting, watching a film: "Can 'being moved' be understood as 'relocation'?" (p. 177). This sensation of temporary 'relocation' of expanded self to something one wants to be could further induce inspiration. Greene [16] in her article "Teaching as possibility: A light in dark times" uses Emily Dickinson's words “The Possible's slow fuse is lit/ By the Imagination" to illustrate those possibilities: "Imagination, after all, allows people to think of things as if they could be otherwise; it is the capacity that allows a looking through the window of the actual toward alternative realities" (p. 2). Even though imagination is a spark that lights a fuse, inspiration is a driving force in most of the artistic processes. Without the inspiration that should ignite the actualization stage, imagination could linger at the daydreaming stage of the aesthetic absorption. Inspiration is the beginning of our 'active participation.' 193). Thus, since we cannot control spectators'

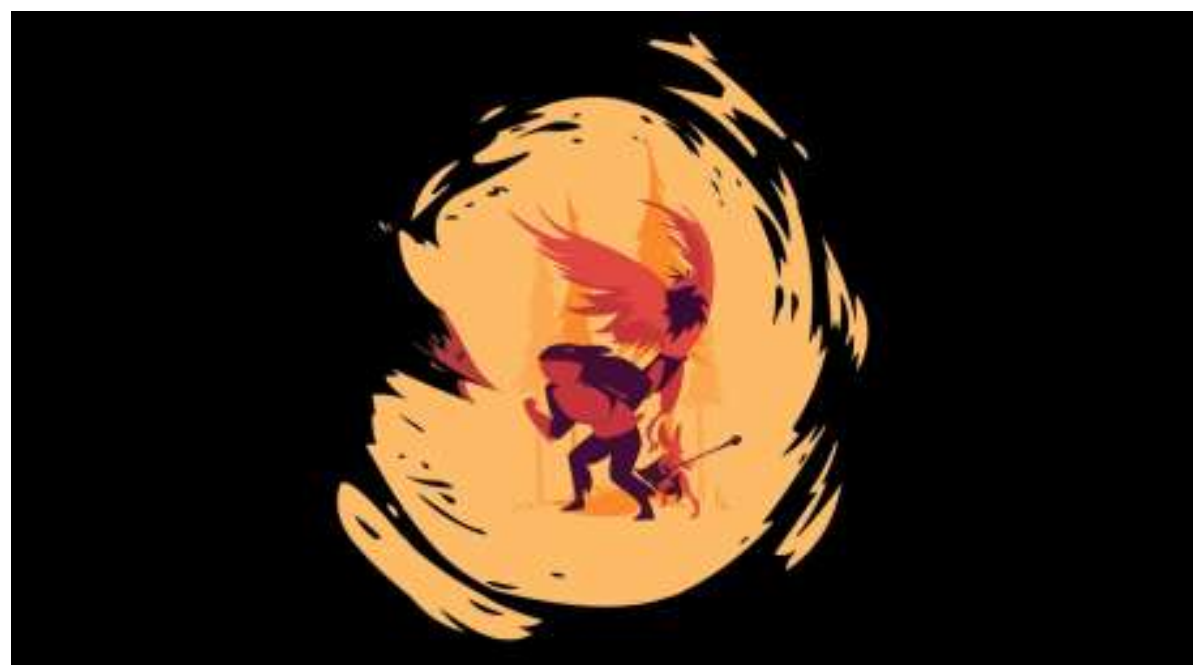

Figure 3. Modern legends, Digital illustration, image published with permission 
Benson [15] believes that:

Our involvement in aesthetic experiences of art is one of active participation. Learning how to participate includes acquiring cognitive skills of reading and symbol-manipulation, social skills of making-believe, empathizing, caring, and critical skills of comparing and judging. A major developmental feature of the ability to participate in and to benefit from the arts, as forms of cultural meaning, is the associated phenomenology of feeling (p. 187).

Benson continues explaining that even though aesthetic experiences of art and generally positive absorption phases are often temporary and short lasting they have very long term outcomes. The phenomenon of 'expansion of self' during these experiences even if brief, allows one to expand to another dimension and when the experience ends it never goes back fully to the previous state. Benson [15] further asserts that "the concept of art is open to unbounded change in its technologies, and in its capacities to shape and require new forms of psychological participation and experience" (p. 193). $\mathrm{He}$ [15] then adds that "forms of art and forms of consciousness constitute each other," yet when people describe their aesthetic experiences they report "a blurring of the boundaries of self" (p. 193) or of the controlling element of self, namely the personal pronoun "I". This phenomenon can be explained by the idea of consciously being relocated to another space/place where this art form exists such as a role for a performing artist or a land/cityscape for a painter. In this process artists are stopping the urge to allow their own predispositions by not deploying their "I" and/or are not responding to the conditions that require the deployment of their "I". Instead they are experiencing positive absorption, a process generally rich with prospects for the expansion of self, potentially better understanding of 'self' as artists.

To encourage novice digital artists as well as my digital arts education colleagues, to reflect and better understand their practices, I often retell a truly inspiring illustration of a master stone builder who already knows which stone to use [15]:

I am watching a master stone builder at work. He is rebuilding an old Irish stone cottage. His materials are filed-stones thrown up by centuries of ploughing and gathered to make ditches and walls. They are of all shapes and sizes and many colours, and were the building materials of the poor. His skills in using them well are highly sophisticated and require a subtle design sense. The walls are in fact double walls, the space between them filled with rubble. Each stone must be chosen according to the space left by the ones already set, by whether filling or capping is needed just here, and by the visual balance of mass as the pattern of the wall emerges. He works according to the plan of height and openings for doors and windows, but within the area of the wall itself each judgement is contingent on what is already there but also a creative judgement setting up succeeding contingencies.

Today the stones are randomly spread on the ground. He places them one at a time, flicks in a mortar, turns to survey what is on the ground, chooses a stone, twists and bends to pick it up, matches it to the space, rotates and positions it and mortars it in. Rarely does he reject a stone he has chosen. The space for the stone and the stone chosen are wedded easily by his visual perceptual and kinesthetic judgement. A new space opens up, a large stone is split with a sledgehammer, its inside is purple. When placed this can be seen to balance another purple stone already in place below to the left. A pleasing look emerges. And so it goes on (p. 32).

If we manage to inspire our novice digital arts students by exposing them to episodes where they will grow even slightly each time they experience positive absorption we can expect to see desirable outcomes. Creation of the new art is necessary not only for our students but for the whole communities because as Dewey [10] warned us that by separating art from the community life and placing it to museums and galleries we are "driving away esthetic perceptions that are necessary ingredients of happiness" (p. 9).

\section{Conclusions and Recommendations}

Exploring this topic and attempting to untangle the complex issue of digital technology in arts processes is an overwhelming task that we are just starting to understand. With the rapid development of wide variety of technological tools becoming available to a broader population traditional artistic processes are becoming obsolete and forgotten. Those particularly vulnerable are the digital native generation which were exposed to these digital tools at the young age and now they are not accustomed to learning using other methods [17]. For this and more reasons concerned educators are discussing possibilities to overcome perceived obstacles within arts education [18].

When introducing art subjects, we are referring to the artistic processes that involve 'feeling' and 'inspiration' and we are hoping that our students will be able to implement them in their projects. However, means of developing social and cultural skills too often come from the popular sources which educators cannot influence such as tent-pole movies or video games that are expected to return profit in a short period of time. As Greene [16] observes: "It is said today that television shows have replaced such common cultural holdings: "David Letterman," "The Today Show," and "Saturday Night Live" shape the culture's conversation, and the "deepest levels of life" are rolled over or ignored" (p. 9).

Still, if our ultimate goal is to create art and to induce emotions we need to do it consciously and with a comprehensive appreciation of the process. 
Traditional and digital arts educators should understand the complexity of the process and more importantly consequences if the process is overlooked. Greene [16] warns us: "There is too much of a temptation otherwise to concentrate on training rather than teaching, to focus on skills for the work place rather than any "possible happiness" or any real consciousness of self" (p. 3). As I stated earlier we need to combat these issues by exposing students to potent aesthetic experiences that would evoke inspiration and imagination and by requiring students to map their artistic expressions first and immerge themselves in the processes after. By investing our energy into young generations we can expect improved educational experiences and the final outcomes. With this alternative view we can also expect them to create new social and cultural capitals to be able to inspire broader populations. With such aspiring descendants and expending technology our future looks promising. Marshall McLuhan, Canadian philosopher and media theorist believed:

I expect to see the coming decades transform the planet into an art form; the new man, linked in a cosmic harmony that transcends time and space, will sensuously caress, and mold and pattern every facet of the terrestrial artifact, as if it were a work of art, and man himself will become an organic art form... we have begun the journey... the story begins only when the book closes [19].

Despite the multiple perspectives on the inquiry of directing technology in digital arts teaching and practice, it is essential to continue to support and join the team that offers the next generation of learners the type of education that will help them better understand their chosen fields. Not only that but also to thrive in the world they live in, and to continue building the future world in the best way possible.

\section{Acknowledgements}

The author would like to thank Mr. Ran Sieradzki, faculty member at LaSalle College Vancouver and his "Modern Legends" team for contributing Figures 2 and 3 (unpublished), and Ms. Judy Wong, graduate student and staff member at SFU for providing her input as directed by the author.

\section{References}

[1] Barnes, T., \& Coe, N. C. (2011). Vancouver as media cluster: the cases of video games and film/TV. In Karlsson, C., \& Picard, R., G. (Eds.), Media clusters: Spatial agglomeration and content capabilities (pp.251276). Cheltenham, UK. Northampton, MA, USA: Edward Elgar Publishing.

[2] The BC Job Makers (2014). Our plan to keep B.C.'s economy diverse, strong and growing is working. Retrieved from http://engage.gov.bc.ca/bcjobsplan/bc- stories/rory-armes-gener8-media-film-technologyvancouver/ (Access Date: 19 September, 2016).

[3] Tech Vibes (2014). BC's tech talent and livability spurring industry growth. Retrieved from http://www.tech vibes.com/blog/bc-talent-livability-industry-growth-201403-10 (Access Date: 24 July, 2014).

[4] Creative BC (2017, March 17). Creative Industry Sector. Retrieved from: http://www.creativebc.com/industr $\mathrm{y}$-sectors/index\#creative-industries-overview (Access Date: 17 March, 2017).

[5] ESAC, Dawson Strategic (2016). Playing for the future: The critical role of skills for Canada's video game industry. Retrieved from: http://theesa.ca/wpcontent/uploa ds/2016/03/DawsonStratESACReportEnglish-Final.2.pdf.

[6] BC Council for International Education (2014). Vancouver one of the world's top places to study media arts. Retrieved from http://www.bccie.bc.ca/vancouverone-of-the-worlds-top-places-to-study-media-arts/ (Access Date: 13 June, 2014).

[7] Patton, R. M., \& Buffington, M. L. (2016). Keeping up with our students: The evolution of technology and standards in art education. Arts Education Policy Review, 117(3), 1-9.

[8] Black, J., \& Browning, K. (2011). Creativity in Digital Art Education Teaching Practices. Art Education, 64(5), 19-34.

[9] Örtegren, H. H. (2014). Digital media added on to the subject of Art in secondary schools. Education Inquiry (Co-Action Publishing), 5(2), 195-214. doi:10.3402/edui.v 5.23227 .

[10] Dewey, J. (1934). Art as experience. New York: Minton, Balch \& Company.

[11] MoCC (2015). Welcome to the museum. Retrieved from http://www.moccguide.net/about/ (Access Date: 21 August, 2015).

[12] Turkle, S. (1991). If the computer is a tool, is it more like a hammer or more like a harpsichord? National Forum. 71(3), 8 .

[13] Coles, L. L., \& Pasquier, P. (2015). Digital eco-art: transformative possibilities. Digital Creativity, 26(1), 315.doi:10.1080/146262268.2015.998683.

[14] Wollheim, R. (2003). What makes representational painting truly visual? Aristotelian Society Supplementary Volume, 77(1), 131-147. doi:10.1111/1467-8349.00106.

[15] Benson, C. (2001). The cultural psychology of self: Place, morality and art in human worlds. New York: NY Routledge.

[16] Greene, M. (1997). Teaching as possibility: A light in dark times. Journal of Pedagogy, Pluralism and Practice, $1(1), 1-10$.

[17] James, C. (2014). Disconnected: Youth, new media, and the ethics gap. Cambridge, MA: MIT Press. 
[18] Gadsden, V. L. (2008). The arts and education: Knowledge generation, pedagogy, and the discourse of learning. Review of Research in Education, 32(1), 29-61.

[19] McLuhan, E., \& Zingrone F. (1995). The Playboy Interview: Marshall McLuhan-A Candid Conversation with the High Priest of Popcult and Metaphysician of Media. In McLuhan, E., \& Zingrone F. (Eds.), Essential McLuhan, (pp.233 -269). New York: BasicBooks. 